\title{
A new conventional regression model to estimate hourly photosynthetic photon flux density under all sky conditions
}

\author{
I. Foyo-Moreno, ${ }^{\text {a* }}$ (1. Alados ${ }^{\mathrm{b}}$ and L. Alados-Arboledas ${ }^{\mathrm{a}}$ \\ " Departamento de Física Aplicada, Universidad de Granada, Spain
}

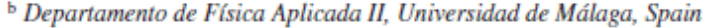

\begin{abstract}
In this work, we propose a new and simple empirical model to estimate photosynthetic photon flux density under all sky conditions, developed using experimental measurements carried out at Granada, an urban site in Southeastern Spain during 2 recent years (2014-2015). The model uses the solar zenith angle and clearness index as input parameters, and thus needs only global irradiance measurements usually registered in most radiometric networks. Five stations located in the Northern and Southern Hemispheres with different climatological characteristics at Europe, Asia and America (Spain, Japan and Argentina) were used to validate the model. The model provides satisfactory results, with low mean bias error (MBE) for all stations, particularly MBE, being less than $1 \%$ in absolute values in three stations and root mean square error below $6 \%$ for all stations except one with $6.1 \%$. These results show better accuracy in comparison with other earlier empirical models and suggest the effectiveness of the model by its general applicability.
\end{abstract}

KEY wORDS photosynthetic photon flux density; global irradiance; solar zenith angle; clearness index

Received 15 October 2016; Revised 17 February 2017; Accepted 21 February 2017 
A new conventional regression model to estimate hourly photosynthetic photon flux density under all sky conditions

6

7 I. Foyo-Moreno, (1), I. Alados (2) and L. Alados-Arboledas (1)

(1) Dpto de Física Aplicada, Universidad de Granada, Granada, Spain.

(2) Dpto de Física Aplicada II, Universidad de Málaga, Málaga, Spain.

Corresponding author:

I. Foyo-Moreno

Departamento de Física Aplicada

Facultad de Ciencias

Universidad de Granada

18071, Granada

Spain.

Phone: 3458240022

FAX: 3458243214

E-mail: ifoyo@ugr.es 
In this work we propose a new and simple empirical model to estimate photosynthetic photon flux density under all sky conditions, developed using experimental measurements carried out at Granada, an urban site in Southeastern Spain during two recent years (2014-2015). The model uses the solar zenith angle and clearness index as input parameters, and thus needs only global irradiance measurements usually registered in most radiometric networks. Five stations located in the northern and southern hemisphere with different climatological characteristics at Europe, Asia and America (Spain, Japan and Argentina) were used to validate the model. The model provides satisfactory results, giving low mean bias error for all stations, particularly Mean Bias Error, MBE, being less than $1 \%$ in absolute values in three stations and Root Mean Square Error, RMSE, below 6\% for all stations except one with $6.1 \%$. These results show better accuracy in comparison to other earlier empirical models and suggest the effectiveness of the model by its general applicability.

\section{KEYWORDS.}

Photosynthetic photon flux density, global irradiance, solar zenith angle, clearness index.

\section{I NTRODUCTION.}

Photosynthetically active radiation is defined as the visible portion of global irradiance $\left(\mathrm{R}_{\mathrm{s}}\right)$ that is utilized by plant biochemical processes in photosynthesis to convert light energy into biomass (Udo and Aro, 1999; Jacovides et al., 2004; Tang et al., 2013). This radiation lies between 400 and $700 \mathrm{~nm}$ and covers both photon and energy terms. Consequently it is 
51 expressed in energy units $\left(\mathrm{Wm}^{-2}\right)$ or photon units $\left(\mu \mathrm{mol} \mathrm{m} \mathrm{m}^{-2} \mathrm{~s}^{-1}\right)\left(1 \mu \mathrm{mol}\right.$ photons $\mathrm{m}^{-2} \mathrm{~s}^{-}$ $52{ }^{1}=6.022 * 10^{17}$ photons $\left.\mathrm{m}^{-2} \mathrm{~s}^{-1}\right)$. Thus, photosynthetic photon flux density, $\mathrm{Q}_{\mathrm{p}}$, is defined as the photon flux density, that is, the number of photons in the 400-700 nm waveband incident per unit time on a unit surface. vegetation, radiation regimes of plant canopy and photosynthesis, playing important roles in

$Q_{p}$ is very important in comprehensive studies of radiation climate, remote sensing of agriculture, atmospheric physics, forestry, ecology, energy management and photon science (Cao et al., 2005). However, reliable measurements of $Q_{p}$ are seldom measured on a routinely basis around the world (Tsubo and Walker, 2005; Ge et al., 2011, Tang et al., 2013). In fact, these measurements are only taken over a few experimental networks, such as FLUXNET (Baldocchi et al., 2001), Baseline Surface Radiation Network (BSRN) (Ohmura et al., 1998), National Oceanic and Atmospheric Administration Surface Radiation Budget Network (SURFRAD) (Augustine et al., 2000), or Chinese Ecosystem Research Network (CERN) (Yu et al., 2006).

$\mathrm{Q}_{\mathrm{p}}$ is strongly affected by the presence of clouds, which are responsible for scattering processes that affect more markedly the shorter wavelengths in the solar spectrum, which include the photosynthetically active spectral range. However, the use of a model including direct information about cloudiness presents the problem that cloudiness observations are usually instantaneous and most irradiance measurements are averaged over intervals between 5 min and 1 hour. Thus, if sky conditions change considerably during the averaging time, the matching of averaged radiation measurements with instantaneous cloud observations may produce confusing results (Calbó et al., 2005). Qp is also affected by atmospheric aerosols, especially under cloudless conditions (Alados et al., 2000), hence it is necessary to model the influence produced by both factors: clouds and aerosols. 

radiometric flux, either radiative transfer models or empirical approaches. The first method implies the application of Mie theory and requires adequate input information regarding cloud optical thickness and drop size distributions at high temporal and spatial resolution; such information is limited to specific sites and campaigns. Furthermore, these spectral models require information concerning aerosol optical properties or an appropriate aerosol model, which is not easily accessible in most radiometric stations. The second method estimates $\mathrm{Q}_{\mathrm{p}}$ from parameters usually measured at most radiometric stations, such as meteorological information and measurements of global irradiance $\left(\mathrm{R}_{\mathrm{s}}\right)$.

For these reasons, one widely adopted method is to model $\mathrm{Q}_{\mathrm{p}}$ from $\mathrm{R}_{\mathrm{s}}$ assuming the ratio between both variables to be constant. However, this ratio presents different values depending on the study area and season (Alados et al., 1996), local time and weather conditions (Akitsu et al., 2015). Different empirical models that use appropriate input parameters for the description of sky conditions can be found in the bibliography. These parameters are indices such as the sky clearness $\left(\varepsilon=\left(R_{d}+R_{b}\right) / R_{d}\right)$, the sky brightness $\left(\Delta=R_{d} / R_{s o} \cos \theta\right)$, or the clearness index $\left(k_{t}=R_{s} / R_{s o}\right)$, where $R_{d}$ is diffuse irradiance, $R_{b}$ is direct normal irradiance and $\mathrm{R}_{\mathrm{so}}$ is the extraterrestrial global irradiance (Pérez et al., 1990; Alados et al., 1996). For example, Tsubo and Walker (2005) proposed a model to estimate $Q_{p}$ with $\mathrm{k}_{\mathrm{t}}$. These empirical models include several meteorological variables such as the dewpoint temperature, or/and water vapour pressure to consider the absorption of radiation by water vapour present in the atmosphere (Alados et al., 1996; Ge et al., 2011, Aguiar et al., 2012). But, in practice these approaches include inherent systematic errors that propagate from their reference (calibration) data and therefore these models are not well established (Akitsu et al., 2015). Moreover, these studies have been mostly conducted at sites in the 
northern hemisphere and few direct measurements have been carried out in the southern hemisphere (Aguiar et al., 2012).

In order to find a simple empirical model to estimate $\mathrm{Q}_{\mathrm{p}}$ from available measurements in most radiometric stations, we have analysed the dependences of the ratio $\mathrm{Q}_{\mathrm{p}} / \mathrm{R}_{\mathrm{s}}$ and $\mathrm{Q}_{\mathrm{p}}$ on different parameters. These parameters are: solar position through the solar zenith angle $(\theta)$, global irradiance $\left(\mathrm{R}_{\mathrm{s}}\right)$, and sky condition. Sky condition includes the effect of clouds and aerosols through the clearness index $\left(\mathrm{k}_{\mathrm{t}}\right)$. To consider the effects of water vapour absorption in this spectral range, we also have analysed the dependence on meteorological parameters such as water vapour pressure (e) or dewpoint temperature $\left(\mathrm{T}_{\mathrm{d}}\right)$.

We propose a simple model which only needs global irradiance measurements as input variable. This model presents the advantage that both variables $\left(Q_{p}\right.$ and $\left.R_{s}\right)$ can be obtained with the same time interval and $R_{s}$ is available in most radiometric stations. The model has been evaluated against a set of independent data at various sites with different climatological characteristic located in the northern and southern hemisphere.

\section{EXPERIMENTAL SITE AND MEASUREMENTS}

Ground-based data from 2014 to 2015 at 1 min intervals were recorded at the radiometric station located on the rooftop of the Andalusian Institute for Earth System Research in Granada (IISTA-CEAMA; $37.17^{\circ} \mathrm{N}, 3.61^{\circ} \mathrm{W}, 680 \mathrm{~m}$ a.s.1.). The year 2014 has been used to develop the proposed model in this work, and 2015 to validate it along with other stations mentioned later. From this data base, hourly values have been generated covering the two-year period, guaranteeing the inclusion of a wide range of seasonal conditions and solar zenith angles. The photosynthetic photon flux density $\left(\mathrm{Q}_{\mathrm{p}}\right)$ was measured using LICOR model 190 SA quantum sensors (Lincoln, Nebraska, USA). Global irradiance, 
$\mathrm{R}_{\mathrm{s}}$, was measured using a Kipp and Zonen model CM-11 radiometer (Delft, Netherlands). The quantum sensor has a relative error less than $5 \%$ estimated by the manufacturer and measurements of global irradiance have an estimated experimental error of about $2-3 \%$. The calibration constants of the instruments were checked periodically. To avoid problems associated to the instrument deviations from the ideal cosine law, we limited our study to solar zenith angles less than $85^{\circ}$ (Alados et al., 1996, Alados-Arboledas et al., 2000).

Granada is a non-industrialized medium-sized located in south-eastern Spain and situated in a natural basin surrounded by mountains with elevations between 1000 and $3500 \mathrm{~m}$ a.s.l.. Near continental conditions prevailing at this site are responsible for large seasonal temperature differences, providing cool winters and hot summers. Most rainfall occurs during winter and spring.

In order to evaluate the proposed model we have used data from different stations not used in the model development, two in Spain (Granada and Jaén), two in Japan (Sapporo and Fujiyoshida) and another one in Argentina (Luján). The quantum sensors used in Jaén (Spain) and Japan are photodiodes (LI-190; Li-Cor, Lincoln, NE, USA) and that in Argentina was an instrument designed by Argentina researchers with similar characteristics to photodiode LI190. Detailed information about instrumentation and sites characteristics can be found in Chamizo et al. (2016) for Jaén (Spain), in Mizoguchi et al. (2014) for Japan and in Denegri (2014) for Argentina. Earlier studies with $Q_{p}$ measurements were conducted in Europe and the Americas, where key climate conditions such as precipitation are different from those in Asia. The stations selected here furthermore cover the northern and southern hemispheres. Thus, model evaluation can be carried out at sites with very different climatic characteristics and altitudes. Table 1 presents some climatic data for stations used in this study. Especially relevant are the differences in yearly precipitation. 


\section{RESULTS AND DISCUSSION.}

150

\subsection{ANALYSIS OF RATIO Qp/ Rs}

Before doing an in-depth, direct study of the variable of interest $\left(Q_{p}\right)$, we have analysed the ratio between $Q_{p}$ and $R_{s}\left(Q_{p} / R_{s}\right)$, as it is a common practice to express $Q_{p}$ as a fraction of $R_{s}$, in order to explore the systematic relationships between both variables. The most important factor influencing the levels of solar radiation reaching the Earth's surface is solar position. Some authors showed that $\mathrm{Q}_{\mathrm{p}} / \mathrm{R}_{\mathrm{s}}$ increases with solar zenith angle $(\theta)$ (e.g. Meek et al., 1984; Udo and Aro 1999) whereas others indicated the opposite (e.g., Ge et al., 2011; González and Calbó, 2002). On the other hand, many authors reported dependences on site or season (Alados et al., 1996; Aguiar et al., 2012; Li e t al., 2010, Jacovides et al., 2003), with higher values in summer and lower values during winter. In any case, the reasons for any dependence of this ratio on solar position remain unclear. Akitsu et al. (2015) found a slight negative correlation $(\mathrm{R}=-0.323)$, but considered it a false correlation caused by the lower solar elevation in winter. Thus, previous reported dependencies on $\theta$ may be attributed to this false correlation or to artifacts (such as cosine and spectral errors) in the quantum sensor and the pyranometers (Akitsu et al., 2015).

Figure 1 shows the dependence of $\mathrm{Q}_{\mathrm{p}} / \mathrm{R}_{\mathrm{s}}$ on $\theta$ through the cosine function. We can observe that this ratio varies between 1.52 and $2.39 \mu \mathrm{mol} \mathrm{J}^{-1}$ with a mean value of $1.95 \pm 0.12$ $\left(\mu \mathrm{mol} \mathrm{J}^{-1}\right.$ ), and with slightly more scatter for longer path lengths. Thus, we find no clear dependence of the ratio $\mathrm{Q}_{\mathrm{p}} / \mathrm{R}_{\mathrm{S}}$ on solar position, even though the mean values tend to higher values for solar position close to the zenith. Alados et al. (1996) also found no dependence on $\theta$ although with more dispersion around the mean value for longer path lengths. 
If we assume this ratio being constant it implies the possibility of a linear model to estimate $\mathrm{Q}_{\mathrm{p}}$ from global irradiance measurements, whose intercept would be zero. This is the simplest model to estimate $\mathrm{Q}_{\mathrm{p}}$ from $\mathrm{R}_{\mathrm{s}}$ with acceptable estimation errors, but the relationship between $\mathrm{Q}_{\mathrm{p}}$ and $\mathrm{R}_{\mathrm{s}}$ changes with cloud condition and season (Mizoguchi et al., 2014). Our mean value is similar to that proposed by Aguiar et al. (2012) in their model $\left(1.94 \mu \mathrm{mol} \mathrm{\textrm {J } ^ { - 1 }}\right)$ although with a non-zero intercept $\left(2.20 \mu \mathrm{mol} \mathrm{J} \mathrm{J}^{-1}\right)$. Bai (2012) found similar mean values for this ratio in two stations in North China: $\left(1.95 \pm 0.12\left(\mu \mathrm{mol} \mathrm{J}^{-1}\right)\right.$ at Yucheng and $1.94 \pm 0.14$ ( $\mu$ mol $\mathrm{J}^{-1}$ ) at Luancheng). Hu et al. (2007) found values between $1.75 \pm 0.12$ to $2.30 \pm 0.15$ $\left(\mu \mathrm{mol} \mathrm{J}^{-1}\right)$ in many places of China.

The ratio $\mathrm{Q}_{\mathrm{p}} / \mathrm{R}_{\mathrm{s}}$ shows scatter values that increase with decreasing $\mathrm{R}_{\mathrm{s}}$ (Figure 2 ). Thus, for high values of $R_{s}$ measurements the ratio tends to a constant value close to the mean value of the ratio $\left(1.95 \pm 0.12\left(\mu \mathrm{mol} \mathrm{J} \mathrm{J}^{-1}\right)\right)$, whereas for a given low value of $\mathrm{R}_{\mathrm{s}}$, the ratio can reach values between 1.52 and $2.39 \mu \mathrm{mol} \mathrm{J}{ }^{-1}$. The ratio $Q_{p} / R_{s}$ shows no dependence on clearness index (Figure 3). This parameter $\left(\mathrm{k}_{\mathrm{t}}\right)$ is defined as the ratio of the global irradiance $\left(\mathrm{R}_{\mathrm{s}}\right)$ to the extraterrestrial global irradiance $\left(\mathrm{R}_{\mathrm{so}}\right)$, both on a horizontal surface:

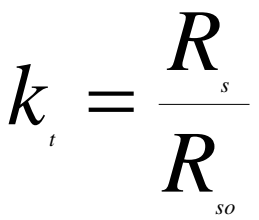

The solar constant value used to calculate $\mathrm{R}_{\text {so }}$ is $1367 \mathrm{Wm}^{-2}$ (Iqbal, 1983). The parameter $\mathrm{k}_{\mathrm{t}}$ characterizes the sky condition including the attenuation effects of the most dominant factors controlling solar radiation, such as clouds and aerosols. Previous studies have used similar parameters such as the sky clearness and the sky brightness (Pérez et al., 1990) to characterize the sky condition (Alados et al., 1996). Despite the lack of dependence, higher values are detected for lower values of $\mathrm{k}_{\mathrm{t}}$ similarly to Figure 2, but with the difference 
of the same high dispersion for the whole range of $\mathrm{k}_{\mathrm{t}}$ values. For $\mathrm{k}_{\mathrm{t}}<0.2$, this ratio can attain values close to $2.5 \mu \mathrm{mol} \mathrm{\textrm {J } ^ { - 1 }}$. In this sense, Tsubo and Walker (2005) found a simple function between both variables in which the ratio increases with decreasing $\mathrm{k}_{\mathrm{t}}$. Also a slight negative dependence $(\mathrm{R}=-0.380)$ was found by Akitsu et al. (2015), a result that can be attributed to the presence of clouds in skies, with high solar absorption in the infrared region. Clouds absorb NIR more strongly than $\mathrm{Q}_{\mathrm{p}}$, hence the transmittance of $\mathrm{Q}_{\mathrm{p}}$ through clouds is larger than NIR. In fact, clouds attenuate more markedly total solar spectral range than shorter wavelengths such as ultraviolet range (Foyo-Moreno et al., 2001, 2003).

Now, to explicitly account for absorption by water vapour on the solar spectrum, we have studied the dependence on meteorological parameters such as the dewpoint temperature $\left(\mathrm{T}_{\mathrm{d}}\right)$ - relevant due to its correlation with the amount of precipitable water (Reitan, 1963) and the partial vapour pressure (e), shown in Figure 4. Our results shows no evidence about the dependence with these parameters, although the mean values tend to higher values with increasing $\mathrm{T}_{\mathrm{d}}$ and e. Akitsu et al. (2015) found positive correlation with e ( $\left.\mathrm{R}=0.847\right)$, with the ratio $\mathrm{Q}_{\mathrm{p}} / \mathrm{R}_{\mathrm{s}}$ increasing with e regardless of sky condition, from 1.9 to $2.2 \mu \mathrm{mol} \mathrm{J} \mathrm{J}^{-1}$ as $\mathrm{e}$ increased from 2 to $30 \mathrm{hPa}$. This increase can be attributed to the absorption of near-infrared radiation by water vapour. The dependence of $Q_{p} / R_{s}$ on e has been roughly described in seasonal variations such as higher values in summer and lower in winter (Rao, 1984; Papaioannou et al., 1996). Alados et al. (1996) found a positive correlation with $T_{d}$, with the ratio $Q_{p} / R_{s}$ increasing as $T_{d}$ increases, because of the enhancement of the extinction process in the infrared region of the solar spectrum. There is a seasonal dependence with higher values in summer and lower in winter, which can be explained by the seasonal pattern of the water vapour content, with higher values in summer and lower values in winter. 
In this section, we directly study the dependence of $Q_{p}$ on the same parameters considered in the above section. First, we show that the solar zenith angle alone does not allow for a correct determination of $\mathrm{Q}_{\mathrm{p}}$ (Figure 5). While $\mathrm{Q}_{\mathrm{p}}$ increases with decreasing $\theta$, due to high dispersion it is possible to parameterise only the envelope of the data through a simple linear dependence on the cosine of $\theta$. The envelope of the data corresponds to the maximum values that can be assumed to values corresponding to clear skies. This relationship is similar to other spectral solar ranges, such as UV or erythemal ultraviolet irradiance (Foyo-Moreno et al., 1998; 2007). So we can propose a linear function to estimate the maximum values of $Q_{p}$ using $\cos \theta$, with the intercept selected as zero. Once the maximum values are determined for a given solar position, the real value will be modulated or attenuated depending on sky conditions (i.e., $\mathrm{k}_{\mathrm{t}}$ ). Consequently, $\mathrm{Q}_{\mathrm{p}}$ measurements can be estimated from a linear expression using the product of two parameters, $\mathrm{k}_{\mathrm{t}}$ and $\cos \theta$, as input data following the procedure used by Foyo-Moreno et al. $(1998,2007)$ with the proposal of a new empirical model to estimate UV and later adaptation to estimate erythemal ultraviolet irradiance extending to other spectral wavelengths ranges. In order to establish a simple model to estimate $\mathrm{Q}_{\mathrm{p}}$, in this work we present a version slightly different.

Following the same scheme until now, we show the high positive correlation between $\mathrm{Q}_{\mathrm{p}}$ and $\mathrm{R}_{\mathrm{s}}\left(\right.$ Figure 6; $\left.\mathrm{R}^{2}=0.998\right)$ as it was anticipated, with a slope of $1.989 \pm 0.001 \mu \mathrm{mol} \mathrm{J}^{-1}$, close to the mean value found for the ratio $Q_{p} / R_{s}\left(1.95 \pm 0.12\left(\mu \mathrm{mol} \mathrm{J}^{-1}\right)\right)$. Similar values for the slope have been found for three sites in Europe by means of data from the EUROFLUX database (Ceulemans et al., 2003). 

on $\mathrm{k}_{\mathrm{t}}$, we were able to parameterize two envelopes for the maximum and minimum possible values of $\mathrm{Q}_{\mathrm{p}}$ at a given value of $\mathrm{k}_{\mathrm{t}}$ (Figure 7). Wang et al. $(2013,2014,2015)$ carried out a

similar analysis and proposed a model including two variables: $\mathrm{k}_{\mathrm{t}}$ and $\theta$. The equation was:

$$
Q_{p}=\left(a+b k_{t}+c k_{t}^{2}+d k_{t}^{3}\right) \cos \theta^{e}
$$

where $a, b, c, d$ and e are the fitting coefficients.

The above analyses demonstrate that it is more appropriate to model $\mathrm{Q}_{\mathrm{p}}$ rather than $\mathrm{Q}_{\mathrm{p}} / \mathrm{R}_{\mathrm{s}}$, and that the determinants parameters are $\theta, \mathrm{R}_{\mathrm{s}}$ and $\mathrm{k}_{\mathrm{t}}$. So we have eliminated the meteorological parameters e and $\mathrm{T}_{\mathrm{d}}$ from our analysis, although some models do consider them (e.g. Aguiar et al., 2012).

Prior to proposing a simple model, we have used Artificial Neural Network (ANN) including the combination of various input data with these parameters to finally select one or more parameters. The combination of input variables taken into consideration in this work were the product $\mathrm{k}_{\mathrm{t}}$ and $\cos \theta$, since Figure 5 showed a linear dependence of $\mathrm{Q}_{\mathrm{p}}$ on $\cos \theta$ for the maximum values of $\mathrm{Q}_{\mathrm{p}}$, and for a given solar position the real value is modulated by $\mathrm{k}_{\mathrm{t}}$ representing broadband transmittance depending on both, cloudiness and aerosol load. This can be viewed as a multivariable interpolation problem requiring estimation of the function relating the input to the output (Alados et al., 2004, 2007). For six model versions, ANN used as input variables: (model 1) $\mathrm{R}_{\mathrm{s}}$, (model 2) $\mathrm{k}_{\mathrm{t}} \cdot \cos \theta$; (model 3) $\mathrm{R}_{\mathrm{s}}$ and $\cos \theta$, (model 4) $\mathrm{R}_{\mathrm{s}}$ and $\mathrm{k}_{\mathrm{t}}$, (model 5) $\mathrm{k}_{\mathrm{t}}$ and $\cos \theta$; and (model 6) $\mathrm{R}_{\mathrm{s}}, \mathrm{k}_{\mathrm{t}}$ and $\cos \theta$. The ANN used in our study is a multi-layer perceptron (MLP) with three layers (input layer, hidden layer and out layer). The optimal number of neurons in the hidden layer was selected following an empirical procedure. The output layer has one neuron, the estimated $Q_{p}$. The design of an ANN requires the use of training and testing data sets. Data from different sites are used in training and selecting the 
best ANN. The validation data set was carried out with data from different stations shown in Table 1. The performance of the models was evaluated using the RMSE (Root Mean Square Error) and the MBE (Mean Bias Error), calculated as percentage of the mean experimental values, given by the following expressions:

$$
\begin{aligned}
& M B E=\frac{100}{M_{\text {ave }}} \frac{1}{N} \sum_{i=1}^{N}\left(E_{i}-M_{i}\right) \\
& R M S E=\frac{100}{M_{\text {ave }}}\left(\frac{1}{N} \sum_{i=1}^{N}\left(E_{i}-M_{i}\right)^{2}\right)^{0.5}
\end{aligned}
$$

where $E_{i}$ is the estimated value ( $i$ th number), $M_{i}$ is the measured value, $M_{\text {ave }}$ is the average of the measured values and $N$ is the number of data. These statistics allow detection of both the differences between model estimates and experimental data, and any systematic data over- or underestimation tendencies. In general, all models present good results with $\mathrm{R}^{2}$ above 0.99 with MBE lower than 5\% and RMSE lower than 10\% (Table 2), but at all sites model 2 presents lower MBE and model 5 lower RMSE; both of these superior models used $\theta$ and $\mathrm{k}_{\mathrm{t}}$ as input variables. Thus, the most adequate variables to model $\mathrm{Q}_{\mathrm{p}}$ are $\theta$ and $\mathrm{k}_{\mathrm{t}}$. Zempila et al. (2016) developed and assessed the performance of linear regression, multiple linear regression and nonlinear neural networks to calculate $Q_{p}$ from $R_{s}$ measurements using also information about $\theta$, the columnar perceptible water vapour and the aerosol optical depth. Jacovides et al. (2015) also used Artificial Neural Network models for estimating daily solar global UV, $\mathrm{Q}_{\mathrm{p}}$ and broadband radiant fluxes in an eastern Mediterranean site.

\subsection{PERFORMANCE OF MODEL.}

Taking into account the already shown results we propose a new simple empirical model to estimate $\mathrm{Q}_{\mathrm{p}}$ through the expression: 
290 with $\mathrm{a}=2681 \pm 2 \mu \mathrm{mol} \mathrm{m} \mathrm{m}^{-2} \mathrm{~s}^{-1}$ and a determination coefficient $\left(\mathrm{R}^{2}\right)$ of 0.999 . The model has been evaluated with experimental data from different stations which were not used in its development, two in Spain (Granada, 2015; and Jaén), two in Japan, and another in Argentina (Table 1). These stations can be considered to represent a wide range of global climatic conditions. Other empirical models include these parameters and others but involving a more complicated formulation. Moreover, small improvements of nonlinear models over linear models have been detected (Zempila et al., 2016).

Table 3 shows the results obtained for each station including the coefficient of determination $\mathrm{R}^{2}$ - the fraction of experimental data variance explained by the model -, the slope $b$, and the intercept a of the linear regression of estimated $Q_{p}$ versus measured values. Table 3 also shows the Mean Bias Error (MBE) and Root Mean Square Error (RMSE), both as percentage of the mean experimental values.

Figure 8 shows $Q_{p}$ estimated via eq. (5) at all localities analysed in this work. The model evaluation is highly satisfactory for all radiometric stations, the variance explained for the models is better than $99 \%$, and the values for MBE and RMSE are low. In fact, for three localities the MBE values are less than 1\%, with larger values at Sapporo (-3.1\%) and Conde (-1.3\%). The RMSE values do not exceed $6.1 \%$. The model underestimates in all locations. In any case, both the slope and correlation coefficient of the linear regression between measured and estimated values reveals the goodness of the model estimations. Wang et al. (2016) developed and evaluated $\mathrm{Q}_{\mathrm{p}}$ estimating models at different types of ecosystems in China, their results showed large differences in model accuracy for each model at each ecosystem. RMSE ranges between 6.45 and $13.08 \%$ and MBE ranges between 4.02 and $8.89 \%$ for a semiempirical all-sky model using as input variables $k_{t}$ and $\cos \theta$. Alados et al. (2000), found MBE 
values about $4 \%$ and RMSE lower than $16 \%$ at two stations located at Granada and Almería using a cloudless parametric model combined with the cloud transmittance, but their scheme requires information about cloud cover.

\section{CONCLUSIONS}

In order to formulate a simple empirical model to estimate the photosynthetic photon flux density $\left(\mathrm{Q}_{\mathrm{p}}\right)$ under all sky conditions, with measurements widely available at most radiometric stations such as global irradiance $\left(\mathrm{R}_{\mathrm{S}}\right)$, this work presents the results showing the dependences of the ratio $\mathrm{Q}_{\mathrm{p}} / \mathrm{R}_{\mathrm{s}}$ and $\mathrm{Q}_{\mathrm{p}}$ with different parameters using the data acquired in Granada, an urban site in Southeast Spain, during two recent years (2014-2015).

The solar position and cloudiness and aerosols conditions are found to be the most important factors to be considered for all sky conditions in order to estimate $\mathrm{R}_{\mathrm{s}}$, and consequently to estimate $Q_{p}$. Our results show no dependence of the ratio $Q_{p} / R_{s}$ on the variables selected, but a certain dependence of $\mathrm{Q}_{\mathrm{p}}$ on them. Based on an analysis using Artificial Neural Network (ANN), including various input data with combinations of these parameters, we propose a simple model using one only input variable, defined as product of the cosine of solar zenith angle $(\cos \theta)$ and the clearness index $\left(\mathrm{k}_{\mathrm{t}}\right)$, which depends both on cloud cover and aerosol load. This model has the advantage of requiring only measurements of $R_{s}$, available at most radiometric stations, and $Q_{p}$ and $R_{s}$ that can be obtained with the same time interval. The model has been evaluated at five stations in Spain, Japan and Argentina, with different climatic characteristics located in the northern and southern hemispheres. The model provides satisfactory results, with low mean bias error for all stations; at three stations Mean Bias Error (MBE) is less than $1 \%$ and the Root Mean Square Error (RMSE) below 
$6.1 \%$ for all stations. These results suggest that this model can be widely applied with better accuracy than other empirical models.

ACKNOWLEDGEMENTS: This work was supported by the Andalusia Regional Government through projects P11-RNM-7186 and P12-RNM-2409, by the Spanish Ministry of Economy and Competitiveness through projects CGL2013-45410-R and CGL2014-52838C2-1-R and by the European Union's Horizon 2020 research and innovation programme through project ACTRIS-2 (grant agreement No 654109). The authors would like to thank the Forestry and Forest Products Research Institute FluxNet Database, FFPRI http://www2.ffpri.affrc.go.jp/labs/flux/), also to Dr. E. Sánchez Cañete by the data from Conde and Dra. M. J. Denegri for the data from Luján.

\section{REFERENCES}

Aguiar LJG, Fischer GR, Ladle RJ, Malhado ACM, Justino FB, Aguiar RG, Costa JMN. 2012. Modeling the photosynthetically active radiation in South West Amazonia under all sky conditions. Theor. Appl. Climatol. 108, 631-640.

Augustine JA, DeLuisi JJ, Long CN. 2000. SURFRAD-A national surface radiation budget network for atmospheric reserach, Bull. Am. Meteorol. Soc., 81, 2341-2358.

Alados I, Foyo-Moreno I, Alados-Arboledas L. 1996. Photosynthetically active radiation: measurements and modeling. Agric. For. Meteorol. 78, 121-131.

Alados-Arboledas L, Olmo FJ, Alados I, Pérez M. 2000. Parametric models to estimate photosynthetically active radiation in Spain. Agric. For. Meteorol. 101, 187-201. 
Alados I, Olmo FJ, Foyo-Moreno I, Alados-Arboledas L. 2000. Estimation of photosynthetically active radiation under cloudy conditions. Agric. For. Meteorol. 102, 3950.

Alados I, Mellado JA, Ramos F, Alados-Arboledas L. 2004. Estimating UV erythemal irradiance by means of neural networks. J. Photochem. Photobiol., 80(2), 351-358.

Alados I, Mellado JA, Foyo-Moreno I, Alados-Arboledas L. 2007. Neural network for estimation of UV erythemal irradiance using solar broadband irradiance. Int. J. Climatol., 27, 1791-1799.

Akitsu T, Kume A, Hirose Y, Ijima O, Nasahara KN. 2015. On the stability of radiometric ratios of photosynthetically active radiation to global solar radiation in Tsukuba, Japan. Agric. For. Meteorol. 290-2010, 59-68.

Baldocchi D, Falge E, Gu L, Olson R, Hollinger D, Running S, Anthoni P, Bernhofer Ch, Davis K, Evans R, Fuentes J, Goldstein A, Katul G, Law B, Lee X, Malhi Y, Meyers T, Munger W, Oechel W, Paw KT, Pilegaard K, Schmid HP, Valentini R, Verma S, Vesala T, Wilson K, Wofsy S.. 2001, FLUXNET : A new tool to study the temporal and spatial variability of ecosystem-scale carbon dioxide, water vapor, and energy flux densities, Bull. Am. Meteorol. Soc., 82, 2415-2434.

Bai J. 2012. Observations and estimations of PAR and solar visible radiation in North China. J. Atmos. Chem., 69, 231-252.

Calbó J, Pagès D, González J. 2005. Empirical studies of cloud effects on UV radiation: A review, Rev. Geohys., 43, RG2002, doi:10.1029/2004RG000155.

Cao MK, Prince SD, Tao B, Li KR. 2005. Regional pattern and interannual variations in global terrestrial carbon uptake in response to changes in climate and atmospheric $\mathrm{CO}_{2}$. Tellus B, 57, 210-217. 
Ceulemans R, Kowalski AS, Berbigier P, Dolman AJ, Grelle A, Janssens IA, Lindroth A, Moors E, Rannik Ü, Vesala T. 2003. Coniferous Forests (Scots and Maritime Pine): Carbon and water fluxes, balances, ecological and ecophysiological determinants, Ecological Studies, 163, $71-97$.

Chamizo S, Serrano-Ortiz S, López-Ballesteros A, Sánchez-Cañete EP, Vicente-Vicente JL, Kowalski AS. 2016. Net ecosystem CO2 exchange in an irrigated olive orchard of SE Spain: influence of weed cover. Agriculture, Ecosystems and Environment (submitted).

Denegri MJ. 2014. Medición de la Radiación Fotosintéticamente Activa (PAR) en planos con diferentes orientaciones, mediante el desarrollo y ensayo de un dispositivo ad-hoc, y verificación de modelos. Doctoral Thesis, pp. 316.

Foyo-Moreno I, Vida J, Alados-Arboledas L. 1998. A simple all weather model to estimate ultraviolet solar radiation (290-385nm). J. Apl. Metereol., 38, 1020-1026.

Foyo-Moreno I, Alados I, Olmo FJ, Vida J, Alados-Arboledas L. 2001. On the use of a cloud modification factor for solar UV (290-385 nm) spectral range. Theor. Appl. Climatol., 68, 41-50.

Foyo-Moreno I, Alados I, Olmo FJ, Alados-Arboledas L. 2003. The influence of cloudiness on UV global irradiance (295-385 nm). Agric. For. Meteorol. 120, 101-111.

Foyo-Moreno I, Alados I, Alados-Arboledas L. 2007. Adaptation of an empirical model for erythemal ultraviolet irradiance. Ann. Geophys., 25, 1-10.

Ge S, Smith RG, Jacovides CP, Kramer MG, Carruthers RI. 2011. Dynamics of photosynthetic photon flux density (PPFD) and estimates in coastal northern California. Theor. Appl. Climatol. 105, 107-118.

González J, Calbó J. 2002. Modelled and measured ratio of PAR to global radiation under cloudless skies. Agric. For. Meteorol. 110, 319-325. 
Hu B, Wang Y, Liu G. 2007. Spatiotemporal characteristics of photosynthetically active radiation in China. J. Geophys. Res., 112, doi: 10.1029/2006JD007965.

Iqbal M. 1983. An Introduction to Solar Radiation. Academic Press: London.

Jacovides CP, Tymvios FS, Asimakopoulos DN, Theofilou KM, Pashiardes S. 2003. Global photosynthetically active radiation and its relationship with global solar radiation in the Eastern Mediterranean basin. Theor. Appl. Climatol. 74, 227-233.

Jacovides CP, Tymvios FS, Papaioannou G, Asimakopoulos DN, Theofilou KM. 2004. Ratio of PAR to broadband solar radiation measured in Cyprus, Agric. For. Meteor., 121(3-4), 135-140.

Jacovides CP, Tymvios FS, Boland J, Tsitouri M. 2015. Artificial Neural Network models for estimating daily solar global UV, PAR and broadband radiant fluxes in an eastern Mediterranean site, Atmos. Res., 152, 138-145.

Li R, Zhao L, Ding Y, Wang S, Ji G, Xiao Y, Liu G, Sun L. 2010. Monthly ratios of PAR to global solar radiation measured at northern Tibetan Plateau, China. Sol. Energy 84, 964973.

Meek DW, Hatfield JL, Howell TA, Idso SB, Reginato RJ. 1984. A generalized relationship between photosynthetically active radiation and solar radiation. Agron. J. 76, 939-945.

Mizoguchi Y, Yasuda Y, Ohtani Y, Watanabe T, Kominami Y, Yamanoi K. 2014. A practical model to estimate photosynthetically active radiation using meteorological elements in a temperate humid area and comparison among models. Theor. Appl. Climatol. 115, 583589.

Ohmura A, Dutton E, Forgan B, Fröhlich C, Gilgen H, Hegner H, Heimo A, König-Langlo G, Mcarthur B, Müller G, Philipona R, Pinker R, Whitlock CH, Wild M. 1998. Baseline 
Surface Radiation Network (BSRN/WCRP): New precision radiometry for climate change research, Bull. Am. Meteorol. Soc., 79, 2115-2136.

Papaioannou G, Nikolidakis G, Asimakopoulus DN, Redalis D. 1996. Photosynthetically active radiation in Athens. Agric. For. Meteorol. 81, 287-298.

Perez R, Ineichen P, Seals R, Michalsky JJ, Stewart R. 1990. Modelling daylight availability and irradiance components from direct and global irradiance. Solar Energy 44, 271-289.

Rao CR. 1984. Photosynthetically active components of global solar radiation: measurements and model computations. Arch. Met. Geophys. Bioclim. Ser. B 34, 353-364.

Reitan CH. 1963. Surface dewpoint and water vapour aloft. J. Appl. Meteorol., 2: 776-779.

Tang W, Qin J, Yang K, Niu X, Zhang X. 2013. Reconstruction of daily photosynthetically active radiation and its trend over China.J. Geophys. Res. Atm., 118, 13292-13302.

Tsubo M, Walker S. 2005. Relationships between photosynthetically active radiation and clearness index at Bloemfontein, South Africa. Theor. Appl. Climatol. 80:17-25.

Udo S, Aro T. 1999. Global PAR related to global solar radiation for central Nigeria.

Agric. For. Meteorol. 97, 21-31.

Wang L, Gong W, Lin A, Hu B, Ma Y. 2013. Measurement and estimation of photosynthetically active radiation from 1961 to 2011 in Central China. Appl. Energy 111, 1010-1017.

Wang L, Gong W, Hu B, Zhu Z. 2014. Analysis of photosynthetically active radiation in Northwest China from observations and estimation. Int. J. Biometeorol., doi: 10.1007/s00484-014-0835-3.

Wang L, Gong W, Feng L, Lin A, Hu B, Zhou M. 2015. Estimation of hourly and daily photosynthetically active radiation in Inner Mongolia, China, from 1990 to 2012. Int. J. Climatol., 35, 3120-3131. 

hourly photosynthetically active radiation in different ecosystems. Renew. \& Sustain. Energy Rev., 56: 436-453.

Yu G, Wen X, Sun X, Tanner B, Lee X, Chen J. 2006. Overview of China FLUX and 459 evaluation of its eddy covariance measurements, Agric. For. Meteor., 137, 125-137. photosynthetically active radiation and global horizontal irradiance using singular spectrum analysis. J. of Q. Spec. \& Rad. Transfer, 182, 240-263. 